\title{
'Waiting and Wanting': older peoples' initial experiences of adapting to life in a care home: a grounded theory study
}

\author{
Marie O’Neill ${ }^{1 \star}$ (D), Assumpta Ryan ${ }^{1}$, Anne Tracey $^{2}$ and Liz Laird ${ }^{1}$ \\ ${ }^{1}$ School of Nursing and Institute of Nursing and Health Research, Ulster University, Derry Londonderry, \\ UK and ${ }^{2}$ School of Psychology, Ulster University, Coleraine, Co Londonderry, UK \\ ${ }^{\star}$ Corresponding author. Email: m.oneill@ulster.ac.uk
}

(Accepted 22 June 2020; first published online 16 July 2020)

\begin{abstract}
A grounded theory approach, consistent with the work of Strauss and Corbin, was used to undertake semi-structured interviews with 17 older people, to explore their experiences of living in a care home, during the four- to six-week period following the move. Purposive sampling was initially adopted, thereafter, theoretical sampling was employed to recruit individuals identified by care managers within older peoples' community teams and care home managers within a large Health and Social Care Trust in the United Kingdom. Consistent with grounded theory methodology, data collection and analysis occurred simultaneously. Constant comparative analysis underpinned data analysis and data management techniques. Data analysis revealed five distinct categories that captured these experiences. These were: (a) wanting to connect - 'I am so lost here', (b) wanting to adapt - 'Well mentally you have to make the best of it', (c) waiting for assistance - 'it's a frustration for me', (d) 'waiting on the end' - I am making no plans' and (e) wanting to re-establish links with family and home - 'I love getting home and I like getting out to the town'. Together these five categories formed the basis of the core category, 'Waiting and Wanting', which encapsulates the initial adaptation experiences of the men and women in the study. Findings indicate that individuals were dependent on others to create a sense of belonging, independence and wellbeing. Moreover, risk aversive practices were perceived as a threat to individuals' independence and autonomy. Recommendations include the need to amend policy and practice for the development of a bespoke induction programme for each resident facilitated by a senior member of the care home staff working in partnership with individuals and families, in addition to the health and social care team, to support a more positive transition for new residents, relatives and care home staff.
\end{abstract}

Keywords: older people; adaptation; care home; transitions; grounded theory

\section{Introduction}

Internationally, it is recognised that adapting to life in a care home environment can be an emotional, complex and upsetting occasion for older people as well as

(c) The Author(s), 2020. Published by Cambridge University Press. This is an Open Access article, distributed under the terms of the Creative Commons Attribution licence (http://creativecommons.org/licenses/by/4.0/), which permits unrestricted re-use, distribution, and reproduction in any medium, provided the original work is properly cited. 
their families (Ellis, 2010; Brandburg et al., 2013; Sury et al., 2013; Ryan and McKenna, 2015;). There is a paucity of research that considers the experiences of individuals in the initial weeks after entry to a care home.

Numerous factors can influence the adaption and adjustment process for older people when relocating to a care home (Bradshaw et al., 2012; Brownie et al., 2014; Križaj et al., 2018; Moore and Ryan, 2017). Some research studies have identified that older people may experience a loss of autonomy, independence and identity, making adaptation to life in a care more challenging. Moreover, older people often struggle to adhere to the routine and rules of the care home environment (Cooney, 2012; Bradshaw et al., 2012; Brandburg et al., 2013; Rieldl et al., 2013; Ericson-Lidman et al., 2014). Several research studies convey that care home environments can be restrictive with a lack of privacy, have limited opportunity for social interaction and have regimented practices (Tsai and Tsai 2008; Bradshaw et al., 2012; Cooney 2012; Križaj et al., 2018). Maintaining continuity between the older person's past and present role has been identified as an important factor in the adaptation process after entry to a care home (Bradshaw et al., 2012; Minhat et al., 2013; Brownie et al., 2014; Križaj et al., 2018). There is also evidence to suggest that individuals may experience a greater sense of freedom, be able to regain some of their independence and feel less of a burden to others (Bradshaw et al., 2012; Sullivan and Willis, 2018). Furthermore, research from older people's perspectives suggests that when faced with upsetting situations, older people attempt to preserve goals, values and relationships, and adapt by using cognitive coping mechanisms, as well as employing practical strategies including maintaining social roles and activities, and receiving support from close ongoing relationships (Tanner, 2010; Clarke and Bennett, 2013).

The transition to a care home environment therefore represents a uniquely significant experience for older people. Brandburg (2007) described three identifiable processes associated with the transition to life in a care home: (a) the initial reaction' or emotional response to the move which is not dependent on whether the admission is planned or unplanned; (b) 'transitional influences' such as life experience and the meaning attached to the relocation; and (c) 'adjustment', where the individual comes to terms with moving, The second and third stages, transitional influences and adjustment, interact and interplay during the process of transition. As a result, older adults are in a dynamic process of adjusting and readjusting as they interact with various transitional influences such as the formation of new relationships with residents and staff. The end of adjustment occurs when the resident comes to terms with living in a care home, has developed new relationships, maintained old friendships and reflected on their new home environment. According to Brandburg (2007), the final 'acceptance' phase usually occurs between six and 12 months post-admission. This marks the end of the transition period when new residents finally accept living in the nursing home. Contrastingly, Bridges (2004) defined transition as a psychological reorientation with three distinct phases: (a) endings that involve letting go and experiencing loss in some form; (b) a neutral zone that is an in-between phase, usually associated with uncertainty; and (c) the new beginning that may involve a new focus or new identity. Furthermore, the 'transition' process has been defined as occurring as a result of change in a person's life continuing until adaptation occurs, producing fundamental changes to an individual's role or identity (Porter and Ganong, 2005; Wiersma and Dupuis, 2010; Paddock et al., 2019). 
Brownie et al. (2014) undertook a systematic literature review to identify the factors that impact on residents' transition and psychological adaptation to longterm care facilities. The review was informed by the concept of home, and Bridges' (2004) three stages of transition framework. Bridges' framework provided conceptual models for better understanding of the needs and aspirations of older people who are in the process of this late-life transition. They identified 19 observational, descriptive and cross-sectional studies exploring older peoples' views about their experiences relocating and adjusting to life in a care home. The majority of studies were undertaken within the first two weeks after entry to the home (Iwasiw et al., 1996; Wilson, 1997; Lee, 1999, 2001, 2010; Heliker and Scholler-Jaquish, 2006; Keister, 2006; Komatsu et al., 2007; Walker et al., 2007; Saunders and Heliker, 2008; Johnson et al., 2010; Walker and McNamara, 2013). Two studies were undertaken within the one- to two-month period post-placement (Wilson, 1997; Komatsu et al., 2007) and another study collected data at monthly intervals up to six months after placement (Saunders and Heliker, 2008). Positive adaptation was reported to be influenced by older people being able to retain personal possessions, continue valued social relationships and establish new relationships within the care facility. A qualitative metasynthesis undertaken by Sullivan and Williams (2017) reviewed eight studies of older adults' transition experiences to long-term care facilities, guided by Meleis's (2010) Theory of Transition. Three themes were identified: loss requiring mourning, stability sought by gaining autonomy and acceptance when inner balance is achieved. A more recent systematic review undertaken by Fitzpatrick and Tzouvara (2019) sought to understand what factors facilitate and inhibit the transition for older people who have relocated to a long-term care facility informed by Meleis's Theory of Transition. Data synthesis of 34 studies using a variety of terms, timelines and study designs identified that transition featured potential personal and community-focused facilitators and inhibitors which were mapped to four themes: resilience of the older person, interpersonal connections and relationships, this is my new home and the care facility as an organisation.

Adaptation to care home life is a process that occurs over a period. Part of understanding this process requires recognition of variances in the responses of older adults. Care home residents are often marginalised and excluded from research (Backhouse et al., 2016). Moreover, there is a paucity of research that takes into consideration the relocation process, incorporating residents' experiences with the move (Sussman and Dupuis, 2012).

This paper is part of an overarching research study which aims to increase our understanding of how older adults make the transition from living at home to a care home over the course of 12 months, at four discrete time-points: prior to or within three days of admission and at three time-points after the move (four to six weeks, four to five months and 12 months). The findings from the first timepoint indicate that older people making the move to a care home are 'at the mercy' of families, health and social care practitioners, and care home staff (O’Neill et al., 2020).

The main limitation of the current body of literature is the dearth of studies on the experiences of the older person in the initial weeks following the move to a care home. The purpose of gathering data at this critical time-point is to elucidate the 
ways in which older people cope with the many changes associated with the move to a care home, e.g. leaving home and being separated from family, friends and communities. This initial post-placement time period often follows a time of crisis, an acute illness or a period of hospitalisation (Wilson, 1997; O'Neill et al., 2020). The way in which individuals are supported (or not) during this time period may have a bearing on their adaptation to life in the care home further down the line. This paper therefore focuses on the four- to six-week period after the move. The knowledge gained from this study has the potential to inform care delivery and policy in determining the initial and ongoing support needs of individuals during this critical time period.

\section{Care home}

In this research study, the term 'care home' is used to encompass both residential and nursing homes. A residential care home provides residential accommodation with both board and personal care for persons by reason of old age and infirmity, disablement, past or present dependence on alcohol or drugs, or past or present mental disorder. They do not provide nursing care. A nursing home is any premises used or intended to be used for the reception of and the provision of nursing for persons suffering from any illness or infirmity. Some homes are registered to care for both people in need of residential and nursing care (Regulation and Quality Improvement Authority, 2020).

\section{Methodology}

Aim

Consistent with grounded theory methodology, the researcher did not identify specific objectives for the study but rather began data collection with a broad aim. To this end, the overall aim of this study was to explore individuals' experiences of moving into a care home with a specific focus on the four to six weeks postplacement period of adjustment.

\section{Study design}

A grounded theory approach, consistent with the work of Strauss and Corbin (1990, 1998), was chosen as it facilitated the development of a new perspective on the experiences of older people in the early weeks after moving to a care home. Grounded theory is recommended when investigating social problems or situations to which people must adapt (Corbin and Strauss, 2008; Morse et al., 2009; Maz, 2013). Grounded theory is an ideal methodology to understand actions and processes through transitions (Morse, 2009), and has been used by qualitative researchers to study processes engaged in by service users (Grant et al., 2009) and family care-givers (Bull and McShane, 2008; Holtslander and Duggleby, 2009; Munhall, 2012). A semi-structured interview schedule was designed to stimulate discussion of individuals' perceptions, thoughts and feelings about their early experiences of living a care home. 


\section{Participants and recruitment}

Purposive sampling was used in the initial stages of recruitment and data collection. Thereafter, and consistent with grounded theory methodology, theoretical sampling was employed to recruit a sample of 17 individuals identified by care managers within older peoples' community teams and by waiting lists held by care home managers within a large Health and Social Care Trust in the United Kingdom. The Trust provides health and social care services to a population of approximately 300,000 people. All nursing $(\mathrm{N}=21)$ and residential homes $(\mathrm{N}=4)$ caring for older people within the study site were registered with the regulatory body and the sample was drawn from this list. The care homes $(\mathrm{N}=8)$ selected were located within both rural and urban areas. Community care managers and care home managers had identified potential individuals who met the study's inclusion criteria in that participants were aware that the move was permanent and they achieved a score of 24 or above on the Mini-Mental State Examination (Folstein et al., 1975). The researcher (MON) obtained written consent and individual face-to-face interviews were arranged at a time and place convenient for each participant. Only one older person invited to do so refused to participate in the study.

\section{Ethics}

Ethical approval for the study was obtained through the Ethics Filter Committee of Ulster University, the Office for Research Ethics Committees Northern Ireland, and the Clinical and Social Care Governance Committee of the Health Care Trust. The Code of Ethics of the International Council of Nurses (2006) has underpinned all aspects of ethical considerations for this study which relate to the protection of vulnerable adults, participants' information, consent, autonomy and confidentiality. A distress protocol was developed, and a system of referral and escalation put into place taking due cognisance of the Protection of Vulnerable Adults guidelines (Department of Health, Social Services and Public Safety, 2006), for implementation should any participant become distressed during interview. The interviews were conducted by the first author who is an experienced mental health nurse and can identify early signs of distress. In addition, participants were asked if there was someone she or he would like to have present during the interview, or who could be a contact person in a case of distress. In the event, no participant became distressed. Some gave emotional responses during the interviews. In adherence to the protocol, the interviewer and participant talked about this, and in each case, the participant wanted the interview to proceed, and indeed felt that talking about their experiences was supportive. The care home manager was informed after the interview if the participant had become upset during the interview. The interviewer did not leave the participant until he or she was content. Informed consent was provided by each participant who agreed to take part in the study with an additional clause giving consent to use a digital recorder for the interviews. Assurances of confidentiality and anonymity were provided and supported by the allocation of pseudonyms in the presentation of the study and its findings. 


\section{Data collection}

Individual face-to-face interviews were arranged at a time convenient for each participant. All interviews were conducted between May 2017 and October 2018. Semi-structured interviews were used to generate discussion that would illuminate ongoing experiences and perspectives from 17 individuals who had moved into a care home. The individual interviews were conducted in private rooms in the eight different care homes. The audio-taped interviews were transcribed verbatim with each interview lasting approximately 60 minutes. Consistent with a grounded theory approach, the semi-structured interviews provided both focus and flexibility (Corbin and Strauss, 2008). Simultaneous data collection and constant comparative analysis were repeated until data saturation was accomplished along with the advancement of theoretical concepts and the development of a core category. As data collection proceeded and the basis of a theory began to emerge, it became necessary to theoretically sample older people in residential and rural care homes as interim findings indicated something diverse about the experiences of older people in care homes within the urban environment. Strauss and Corbin (1998: 201) have described theoretical sampling as a means to 'maximise opportunities to discover variations among concepts and to densify categories in terms of their properties and dimensions'. Therefore, potential participants moving to these types of care homes were invited to take part in the study. The process of theoretical sampling continued until the emerging concepts and categories reached saturation.

The interview schedule evolved commensurate with category and sub-category dimensions using the grounded theory approach. Prompts were used to generate discussion and included:

- Tell me about how you are getting on since you moved into the care home?

- Tell me about how you keep in contact with your family and friends at home?

- How has your life changed since living in this care home?

- Can you tell me about any concerns and/or worries you may have about living here now?

- Prompts on physical, psychological and social wellbeing since admission.

\section{Data analysis}

The interviews were recorded and checked to ensure the rigour of the data collection procedures. NVivo 12 qualitative data analysis program software (QSR International, 2018) facilitated the organisation, management and retrieval of transcribed interviews and field notes, and provided tools for coding, categorising and linking qualitative data. Constant comparative analysis underpinned data analysis and data management techniques. Repeated ideas, concepts or elements became apparent, and were tagged with codes extracted from the data. Grouping of codes into concepts and then into categories was undertaken after more data collection and review. As analysis progressed, coding moved towards being 'selective', focusing on those codes which related to emergent main categories. In the final stage of coding, the process of identifying and choosing the core category occurred by systematically connecting it to other categories and validating those similarities 
After the selective coding process, trustworthiness of the data was enhanced by all the research team who reviewed themes and discussed alternative interpretations of the data to maximise credibility, dependability and confirmability (Lincoln and Guba, 1985). In keeping with one of the tenets of grounded theory (Corbin and Strauss, 2008), individuals' own language at all levels of coding was used to further ground theory construction and add to the credibility of findings.

\section{Findings \\ Profile of individuals}

The 17 individuals who participated in this study comprised ten women and seven men with an average age of 83.3 years. Seven of the individuals were transferred from hospital to the care home and the others were relocated directly from their home. The majority of the individuals $(\mathrm{N}=13)$ were living alone at the time of admission while the minority $(\mathrm{N}=4)$ lived with spouse/family members.

The main reasons cited for prompting the relocation to a care home was deterioration in physical health $(\mathrm{N}=11)$, recent bereavement $(\mathrm{N}=3)$ and no-one to take care of me/changing family circumstances $(\mathrm{N}=3)$. Only four of the 17 participants stated that they had made the decision to move to a care home, and of these four, only two were able to move to the care home of their choice. Demographic details of individuals and reason for admission are outlined in Table 1.

\section{From concepts to categories}

This paper reports key findings pertaining to the experiences of 17 older people within the four- to six-week post-placement period in a care home. Data analysis revealed the following five distinct categories: (a) wanting to connect - 'I am so lost here', (b) wanting to adapt - 'Well mentally you have to make the best of it', (c) waiting for assistance - 'it's a frustration for me', (d) 'waiting on the end' - I am making no plans' and (e) wanting to re-establish links with family and home - 'I love getting home and I like getting out to the town'. Together these five categories formed the basis of the core category 'Waiting and Wanting' which encapsulates the overall experiences of adjusting to life in a care home, for the men and women in this study. Individuals asserted that they were wanting to connect with others and self, and make sense of the adjustment, waiting to take control of their independence and avoid dependence, waiting on what the future may hold and wanting to reconnect with home and community. Figure 1 shows the relationship of major categories to each other and to the core category.

\section{Wanting to connect - 'I am so lost here'}

Undeniably moving to a care home where the future might appear uncertain is regarded as one of the most daunting and difficult challenges an individual can face in their later life. Some individuals were experiencing a longing for human connectedness in their new environment: 
Table 1. Characteristics of the interviewees and details of admission

\begin{tabular}{|c|c|c|c|c|}
\hline Pseudonym & Age & $\begin{array}{l}\text { Living arrangement } \\
\text { prior to move }\end{array}$ & $\begin{array}{l}\text { Individuals account of details surrounding } \\
\text { admission to care home }\end{array}$ & How was admission arranged? \\
\hline Jane & 84 & $\begin{array}{l}\text { Lived alone in rented } \\
\text { accommodation }\end{array}$ & $\begin{array}{l}\text { 'Too old to be on my own and I'm frightened of } \\
\text { falling.' Jane developed a chest infection, was } \\
\text { admitted to hospital and then had poor } \\
\text { mobility }\end{array}$ & $\begin{array}{l}\text { Family arranged admission through } \mathrm{GP} / \text { social } \\
\text { worker. Did not visit care home prior to admission }\end{array}$ \\
\hline Ellen & 82 & $\begin{array}{l}\text { Lived alone in rented } \\
\text { accommodation }\end{array}$ & $\begin{array}{l}\text { Husband died recently, wanted to move to } \\
\text { sheltered housing. Nursing home was only } \\
\text { available choice }\end{array}$ & $\begin{array}{l}\text { Social worker arranged admission. Ellen wanted } \\
\text { sheltered accommodation, but care home was } \\
\text { offered as only accommodation available. Did not } \\
\text { see care home prior to admission }\end{array}$ \\
\hline David & 88 & $\begin{array}{l}\text { Lived alone in family } \\
\text { home }\end{array}$ & $\begin{array}{l}\text { Chose care home as wife already there a year } \\
\text { previously. Health deteriorated after a fall at } \\
\text { home, 'I'm too old to be on my own' }\end{array}$ & $\begin{array}{l}\text { Chose care home for his wife in the first instance } \\
\text { then when his health deteriorated he planned the } \\
\text { move }\end{array}$ \\
\hline Bernadette & 92 & $\begin{array}{l}\text { Lived alone in family } \\
\text { home }\end{array}$ & $\begin{array}{l}\text { Had fall at home, admitted to hospital. 'Family } \\
\text { thought it was not right for me being on own. } \\
\text { Mobility poor - "Doctor says move in"' }\end{array}$ & $\begin{array}{l}\text { Daughters visited the home and recommended it to } \\
\text { Rita. GP and social worker decided. Rita did not visit } \\
\text { home prior to admission }\end{array}$ \\
\hline Andrew & 82 & $\begin{array}{l}\text { Lived alone in family } \\
\text { home }\end{array}$ & $\begin{array}{l}\text { Wife died, had recent stroke, was taken to } \\
\text { hospital. Family overseas }\end{array}$ & $\begin{array}{l}\text { Daughter came home and visited local care homes. } \\
\text { Andrew in hospital prior to admission but did not } \\
\text { visit care home }\end{array}$ \\
\hline Martha & 80 & Lived alone at home & $\begin{array}{l}\text { 'Fell at home, needed a new hip.' Changing } \\
\text { family circumstances - no-one now at home }\end{array}$ & $\begin{array}{l}\text { Social worker arranged admission. Only care home } \\
\text { available. Did not visit care home prior to admission }\end{array}$ \\
\hline Sean & 60 & $\begin{array}{l}\text { Lived with wife and } \\
\text { children in family } \\
\text { home }\end{array}$ & $\begin{array}{l}\text { Developed sepsis, progressed to paraplegia with } \\
\text { lesion on spine. Total nursing care required. } \\
\text { Facilities at home do not support nursing care }\end{array}$ & $\begin{array}{l}\text { Was transferred straight from hospital to care home } \\
\text { which was only one available to meet care needs. } \\
\text { Did not visit care home prior to admission. }\end{array}$ \\
\hline Tracey & 88 & $\begin{array}{l}\text { Lived alone in rented } \\
\text { accommodation }\end{array}$ & $\begin{array}{l}\text { Getting worried about deterioration in health or } \\
\text { falling, chose residential care admission }\end{array}$ & $\begin{array}{l}\text { Arranged through social worker who took Rose to } \\
\text { see a few care homes and she chose the one she } \\
\text { liked the most }\end{array}$ \\
\hline
\end{tabular}

(Continued) 
Table 1. (Continued.)

\begin{tabular}{|c|c|c|c|c|}
\hline Pseudonym & Age & $\begin{array}{l}\text { Living arrangement } \\
\text { prior to move }\end{array}$ & $\begin{array}{l}\text { Individuals account of details surrounding } \\
\text { admission to care home }\end{array}$ & How was admission arranged? \\
\hline Molly & 80 & $\begin{array}{l}\text { Lived alone in rented } \\
\text { accommodation }\end{array}$ & $\begin{array}{l}\text { 'Developed anxiety'. GP advised admission, } \\
\text { 'feeling safe now' }\end{array}$ & $\begin{array}{l}\text { Was being placed by social worker in a care home a } \\
\text { few miles away from her family. Molly waited on a } \\
\text { vacancy becoming available locally. Did not visit } \\
\text { care home prior to admission }\end{array}$ \\
\hline Charles & 83 & $\begin{array}{l}\text { Lived with wife in } \\
\text { rented } \\
\text { accommodation }\end{array}$ & $\begin{array}{l}\text { Wife died suddenly who was carer. Had been in } \\
\text { a wheelchair for many years due to war injury. } \\
\text { Admitted to care home on day of wife's death in } \\
\text { a taxi }\end{array}$ & $\begin{array}{l}\text { Charles was admitted to the care home the night his } \\
\text { wife died as she was his carer. It was an emergency } \\
\text { admission and he had no say in the move nor did he } \\
\text { visit the care home prior to admission }\end{array}$ \\
\hline Anne & 90 & $\begin{array}{l}\text { Lived alone in own } \\
\text { home }\end{array}$ & $\begin{array}{l}\text { Admitted to hospital with transient ischaemic } \\
\text { attack, then transferred to nursing home. 'I had } \\
\text { no choice' }\end{array}$ & $\begin{array}{l}\text { Was moved to a nursing home initially post-hospital. } \\
\text { Anne asked social worker for a transfer to residential } \\
\text { care. Did not visit the care home prior to admission }\end{array}$ \\
\hline Isobel & 96 & $\begin{array}{l}\text { Lived alone in rented } \\
\text { accommodation }\end{array}$ & $\begin{array}{l}\text { Chest infection, admitted to hospital. Reduced } \\
\text { mobility in hospital. Son working away }\end{array}$ & $\begin{array}{l}\text { Isobel stated she would have needed carers at home } \\
\text { so social worker asked where she would like to go. } \\
\text { Requested care home next to home but no } \\
\text { vacancies. Did not visit care home prior to admission }\end{array}$ \\
\hline Tony & 87 & $\begin{array}{l}\text { Lived alone in family } \\
\text { home }\end{array}$ & $\begin{array}{l}\text { Developed pneumonia and was admitted to } \\
\text { hospital. GP advised admission to care home }\end{array}$ & $\begin{array}{l}\text { GP and social worker arranged admission. Tony } \\
\text { knew of care home because it was local but did not } \\
\text { visit the care home prior to admission }\end{array}$ \\
\hline Hugh & 83 & $\begin{array}{l}\text { Lived alone in family } \\
\text { home }\end{array}$ & $\begin{array}{l}\text { Accident at home, admitted to hospital. } \\
\text { Reduced mobility. Niece lives far away }\end{array}$ & $\begin{array}{l}\text { Hugh stated pressure 'to release hospital bed' so his } \\
\text { niece visited a few care homes and made } \\
\text { arrangements for admission which is } 30 \text { miles from } \\
\text { Hugh's home. Did not visit care home prior to } \\
\text { admission }\end{array}$ \\
\hline
\end{tabular}




\begin{tabular}{|c|c|c|c|}
\hline Mona & 81 & $\begin{array}{l}\text { Lived at home with } \\
\text { daughter }\end{array}$ & $\begin{array}{l}\text { Poor mobility for many years. Daughter (carer) } \\
\text { fell and injured back requiring hospital } \\
\text { admission }\end{array}$ \\
\hline Kevin & 83 & $\begin{array}{l}\text { Lived alone in family } \\
\text { home }\end{array}$ & Fell while shopping, taken to hospital \\
\hline
\end{tabular}

Mona was admitted to the care home the day her daughter fell and sustained fractures requiring prolonged hospital admission. Her daughter was her carer. It was an emergency admission and she had no say in the move nor did she visit the care home prior to admission

Hospital staff advised residential care home admission arranged by social workers. Did not visit care home prior to admission

Note: GP: general practitioner. 
I have been doing nothing here, I just sit here and wait for people to come and visit me. (Mona)

Others felt out of place, citing other resident's cognitive impairment and frailty as a fundamental obstacle to social engagement:

I am so lost here, it's not me, it's not home and it's so big, I don't really know where I am at now. It is very hard to find your way. Some of them, but not all of them are beyond making friends, they are not sick, they're old, so they're not good anymore, you have to take your pick. (Ellen)

For some individuals the importance of forming new relationships was seen as being crucial to one's sense of 'identity' and 'connectedness' to people within their new home:

I am just friendly with everyone. I like being friends with people and that is very important to me as I am coming in here as an outsider. (Tracey)

I know I didn't expect to settle quickly, but it's taking a bit longer than I thought it would. I was a bit disappointed when I came because I didn't know any people and I thought that I would. But I've got to know some people now, but I still want to go home. (David)

It was apparent that for some individuals their 'sense of self was enhanced or reduced through their interaction with and observations of other residents and their reactions to others' behaviour:

It's not home. Everybody says the same, it's great and all that but it's not your own. There's an old lady I met since I came in, she likes me and every morning I must get up and wave to her in the dining room. I suppose when you look at it there are people far worse off than me. Some of them can't even hold the cup up in their hands. (Bernadette)

I'm not really settled here. You see there is no-one here that I could honestly feel that I could be friends with ... so that's it. (Charles)

It was evident that care home staff were primarily perceived as providers of health care delivery only and not as people with whom to develop relationships:

Well they only come in to do tasks and go out again. You don't develop a relationship with them. (Sean)

Some individuals wanted to 'ease the transition' to living in the care home by spending parts of the day outside the home with family:

I suppose I will have to get settled here I have no choice. My sister comes and takes me out for a while every day so thank god for that. I have to get out of here even just for a while. I know that I have to get used to it in here, but it would be too long for me if I had to spend the whole day in here every day. (Molly) 
It is evident that maintaining one's identity and autonomy are considered significant factors in an older person's experience of moving into a care home. Some participants were taking steps to 'fit in' and 'feel their way' within this new environment:

I suppose you just have to get on with people, well if you don't it is bad, but thank god I do. I don't go down and sit all day in the big room looking at TV. That's not my thing. And maybe they think I should, but I go down every so often so that they don't think that I'm not mixing. But when I go down there's only two or three of them there sound asleep, so I come back up again. And the others must do the same. (Anne)

\section{Wanting to adapt - 'Well mentally you have to make the best of it'}

Having a positive attitude towards care home admission can be supported by hospital staff who discussed with one participant, Gerard, the necessity for the move. They provided him with information about the home and discussed the practicalities of the move, thus making it easier for him to become accustomed to a new way of living in the future:

Oh, I love it here I really do. I was told by the staff in the hospital that when you go over to [care home] you will love it. They are a sort of family here you know. Everybody speaks to each other and they are all good to each other. I do tell them that too you know. (Gerard)

There was a sense of individuals making the new home meaningful by bringing in possessions and photographs to symbolise their identity. Continued identification with such meaningful symbols helped to sustain identity:

I suppose I am starting to get used to it now a bit. I am trying anyhow. It is very different you know from being at home with your own people. I have brought some photos here now as well and my bed throws, I like them. I would have liked to bring more but you really don't have much room you know. (Isobel)

Individuals expressed their own sense of self-efficacy, personal resilience and ways of coping with adjusting to life in the care home, by taking 'one day at a time' and mentally 'making the best of it':

Well I always take it one day at a time and thank god it's been good so far. It's the best way to take it, you know, because I wouldn't be doing as well as I'm doing otherwise, you see, I would miss things from home. Well I do a lot of thinking but sure that's no harm. (Anne)

You have to try and accept being here you know but it is very hard, really hard ... it's psychological, but you feel like you are at the end of the road, you know. Well mentally you have to make the best of it that's the main thing. Firstly, settle into the illness, clear your head and your mind and you will get by, otherwise, you would just be depressed. (Andrew) 
A strong part of facing reality for some individuals involved resisting having decisions taken away from them, proposing to fight for their independence and sense of identity:

My life has to change. I cannot leave everything to the doctors. I have to get myself better then I will think differently. I am not thinking properly now, I'm not right yet, I feel scared of everything. I'm not there yet, I have to say to myself that I can still have a life. (Ellen)

Some Individuals were moving towards acceptance of being in a care home, often accompanied by tears as the reality dawned on them that they would not be returning to their home:

Well, you know, I hope I will settle. Some nights I would sit down and have a wee cry to myself. I know now that I have to stay in here because I can't stay on my own. I'm reconciled to that now ... I have to be. (Bernadette)

Others were putting on a brave face for the care home staff and their family:

It's easier to smile than cry. You've a lot to answer for after you've cried, you know, was that necessary ... well I have to put on a brave face for my wife and the people here. You see my wife she has been through so much in the past year and she has never failed me. I would fail her if I broke down ... and the staff well you see they expect you just to get on with it, pull yourself together like. (Sean)

Other individuals were self-assured in the decision they had made to move to a care home. Reflecting on the positive elements of the relocation, opportunities were identified to form new relationships, gain staff support with aspects of care, and pursue former hobbies and activities:

Life is sort of different now. I am content now; I will not be going anywhere else ... They let you do what you want and don't force you to do anything, I like that ... you see that's me ... Moving here is the right decision for me. I know now that I had to leave the house. At the end of the day it is only bricks and mortar. (Gerard)

Yeah, it's good to get someone to do something for you. It takes the pressure off me. I feel safe here. I like going out for a walk ... you know I am just happy with the little things. (Tracey)

However, some individuals considered their self-determination at risk because they felt restricted by care home routines and practices which was experienced as a feeling of powerlessness:

I do think that there are too many rules when you are living here. It is a big change for me to live away from my home and my life. I am not sure if it is a good change ... I suppose time will tell. (Andrew) 


\section{Waiting for assistance - 'It's a frustration for me'}

Individuals talked about how having to wait on care services had a negative effect on their individuality and independence, and curtailed them from making the progress they would have liked:

The stroke nurse who was to do the swallowing test never came. She was to sign me off for swallowing so that I could eat bread ... You see I am very determined to be as independent as I can be? I would love to be able to walk to the toilet on my own. I would just like more progress. Every time I get a chance to walk and work at my arm, I take it, I do all the physio exercises that I am told. (Therese)

I am lost without my glasses because reading is very important to me so without them ... well what else can you do? I read all my life and I miss that. I hope that they get here soon. The fella tested my eyes weeks ago, but I haven't heard a word about it since. I'm just wondering what's happening and that they have been ordered because I need them. (Tracey)

Aspiring to maintain independent physical function was important to some individuals who were happy with improvements in their health following physiotherapy and self-governed exercise routines, while others were frustrated about losing progress made while in hospital, making them more dependent on staff for assistance:

They got me walking in hospital, but they don't do that here. I have never been up walking and they don't give you physio ... and it's awful when they let you go on ringing that bell and just ignore you, and you have been waiting for over an hour and nothing happens. I have had to phone my family to tell them to phone the home and ask them to answer the bell! (Andrew)

I've just been plodding along day to day, it's the same day well every day really, I feel trapped. I have to depend on so many people. Just even to get out of bed. My wife does my physio when she comes in, especially my legs. (Sean)

Care home restrictions, standardised routines and 'risk-aversive practices' threatened individuals' independence and autonomy, and generated frustration and passivity in waiting for assistance:

I like to do as much ... well as much as I can for myself. But they don't like it, for me to be independent. The staff will treat you well, but some of them are like the Gestapo ... kind of serious, they don't ask you nicely to do something. They sort of demand you do things because we have to sort of answer to their call you know, so you don't want to give them too much reason to be annoyed with you, I don't anyway. (Charles)

It's a frustration for me having to wait on the staff and ringing that bell. Some of the nurses are nice. But if you need help, they aren't in a hurry. I am getting to know who to ask now. (Ellen)

Although I have a Zimmer frame, I still have to have someone to take me to the toilet, I'm not allowed to walk on my own, but I think I'm fit to walk on my own. I feel restricted I think that's my main problem. (David) 


\section{Waiting on the end - 'I am making no plans'}

Some individuals expressed feelings of hopelessness and despair about the future, seeing no purpose when their physical, mental and social abilities were diminished:

I am getting to the stage that I don't want to go on. I can't go on like this, I am in a lot of pain. (Mona)

For others these feelings varied; one participant recognised how on admission she wished for death. This was a personal reflection of psychological wellbeing at that time:

I was so down when I first came here. The nurse when she came last week, she said I had changed, that I was getting better ... Well less depressed. I know that at first, I was bad, I was trying to write a suicide note, I was scared. (Ellen)

Death was an inevitable part of life for many individuals who often said they were taking each day as it comes and not worrying too much about tomorrow:

I don't know what is going to happen in the future. I always thought that I wouldn't like to die a sudden death. I would like to be ready for death. But other than that, I don't think too far ahead. (Bernadette)

I am making no plans. If I am here tomorrow, then I am here tomorrow and that's it. I have had a good life. Every day I go to bed I say to myself I wonder will you be here in the morning. (Tony)

Accordingly, for some individuals, death and dying framed their present outlook on life. Some spoke about 'of being on borrowed time', 'feeling ready to die' and some even welcomed it:

I don't see much of a future I don't have anything to look forward to ... I look forward to when I would die. I don't think I will last that long; I don't know. Well I have a chest problem and a blood problem. I am happy to go whatever happens. (Charles)

My life is different here. I don't see ... well at my age now, I don't see much future except death. I wasn't very well this last while ... I was telling them I was going to die. (Jane)

As individuals observed contemporaries' deaths, a heightened awareness of dying became evident:

The staff here keep it very quiet if someone is ill. I've noticed that when you're waiting for someone to die, there's hints, for example there's the trolley arriving, when you see that you know that someone is seriously ill ... But you are disappointed if there's a death here. There was one last week, everyone feels it. There's another lady ill now, it puts us off, and we're not in the same good humour. (David) 
For some, experiencing a loss of family created an awareness of their own mortality:

My sister died recently, it was a big loss to me you know but what can you do, if god wants them, he takes them. That's the way ... sure, our own day will come. (Isobel)

\section{Wanting to re-establish links with family and home - 'I love getting home and I like getting out to the town'}

Maintaining links with family, friends and communities was important to reinforce a sense of self and to safeguard against a threatened identity or wellbeing:

I have a cousin who comes in ... Emily, she comes in. She lives close by, so it is nice to see her. My niece used to come down every day at the beginning, but I hardly see her now. (Mona)

I suppose at my age there isn't much to look forward too, but I look forward to seeing my family coming in. I haven't been out since I came here, it would be nice just to go home for a while to see them and have my dinner. (Isobel)

There was recognition of the inevitability and need 'to get settled' in the care home on a gradual basis, while maintaining links with family which was also identified:

I suppose what will help me settle is...well I like to be independent and do my own thing you know...so I hope that I will be able to keep doing that here as I need to keep getting out and about and doing the things that I want. You see I like meeting people, I always have done and going out with my sisters. (Molly)

Individuals experienced a dependence on both staff and family to get out or come into the care home to 'see family', 'see my home', 'go to the chapel', 'go shopping' or just 'be in the garden':

I haven't been out since I've been here. It's such a bother, I think we will have to wait to the summer to someone brings us out. The staff said it's too cold to go out now ... But my niece comes to see me every week and then I have other visitors come too. (Martha)

I would really like to go to the chapel, but I can't go on my own. Well not at present with my foot ... but I could go out in a wheelchair if someone would take me. I don't think there is anybody that would do that here. (Isobel)

I haven't been out home since I came here. They probably think that it would upset me too much ... I like my family coming to visit. I would like to get outside to be in the fresh air and to get out for a run home to see the house and the neighbours. (Andrew)

Most individuals expressed the view that they wanted to maintain social contacts outside the care home to maintain identity-affirming connections and be part of the community: 
I love getting home and I like getting out to the town you know. I just like to see if there is any building going on or what's happening in the town. (Tracey)

A lot of people come at the beginning to see you when you move into the home, but it tails off after that. My nephew took me out to tea that was good. I like getting out, it is a nice change. My other niece will be back to see me this coming week. (Therese)

\section{Discussion}

As there is limited research that incorporates residents' experiences during the initial weeks following entry to a care home (Lee et al., 2002; Fraher and Coffey, 2011; Johnson and Bibbo, 2014; Sussman and Dupuis, 2014), this study set out to explore older peoples' experiences of the first four to six weeks following the move. Five distinct categories captured the experience of the four- to six-week post-placement period. These were: (a) wanting to connect - 'I am so lost here', (b) wanting to adapt - 'Well mentally you have to make the best of it', (c) waiting for assistance 'it's a frustration for me', (d) 'waiting on the end' - I am making no plans' and (e) wanting to re-establish links with family and home - 'I love getting home and I like getting out to the town'. Together these five categories formed the basis of the core category 'Waiting and Wanting' which encapsulates the perceived transitional experiences of the men and women in the study. The core category of 'Waiting and Wanting' provides descriptions of individuals experiences of 'wanting' to reconnect with their family, friends, home and community, and 'waiting' to make sense of the process of adaptation, while taking control of their lives and avoiding dependence. The core category connects to emergent categories which encompassed descriptions of individuals' senses of identity, connectedness with others, autonomy and caring practices.

Within this study the period of adaptation following the move to the care home was viewed by many individuals as leading to a loss of independence, autonomy, decision-making, meaningful engagement and continuity of former roles. Moreover, the loss of an individual's home life presented a major challenge threatening identity, belonging and sense of self (Lee et al., 2013; Brownie et al., 2014; Paddock et al., 2019), and for many a sense of belonging was taking time to develop (Lindley and Wallace, 2015). Individuals were clearly 'wanting' to connect with others in this new environment, and at the same time 'wanting' to re-establish links with family and home. Numerous studies have found that leaving home and being separated from family and communities compounds these losses and feelings of isolation (Iwasiw et al., 1996; Lee, 1999; Bland, 2005; Heliker and Scholler-Jaquish, 2006; Saunders and Heliker, 2008; Fraher and Coffey, 2011; Hutchinson et al., 2011). Adapting to a care home's 'rules and regulations' and being subjected to 'waiting' for assistance were sources of frustration. The need to 'learn the ropes' is an additional source of stress and anxiety for some individuals (Wilson, 1997; Lee, 2001; Heliker and Scholler-Jaquish, 2006).

Many anxieties, including health and social issues, can affect the adaption and adjustment process for older people after moving to a care home (Bradshaw et al., 2012; Brownie et al., 2014; Križaj et al., 2018). Within this study, some 
individuals experienced emotional responses in their early weeks of living in the care home, reporting 'It's hard to find your way', 'I am so lost here'. These experiences have been previously identified by Bridges (2004) when considering the early transition stages of moving to a care home, i.e. an ending; and a period of confusion which can lead to high anxiety levels; and a new beginning. Within this study, individuals whose relocation experience was deemed to be positive, expressed hopeful affirmations 'Life is sort of different now. I am content now', 'Oh, I love it here I really do'. It has been recognised within Brandburg's (2007) transition process framework how an initial reaction to the move can be marked by emotional responses, and how personal characteristics, values, the history and admission circumstances can influence transitional experiences thereafter. The findings of this study resonate with the first two stages of Brandburg's (2007) transition process framework in that the first stage identifies an initial reaction to the move that is marked by emotional responses; and the second stage as transitional influences, e.g. personal characteristics, values, history and circumstances of admission. Within this context, most individuals within this study identified that adapting to life in a care home was an ongoing process that for the main part they were trying to navigate themselves with little support from care home staff or others. This was perceived by individuals as an upsetting and worrying experience during the four- to six-week adaptation phase of settling into life in a care home.

Meleis's theory of transitions explains how a person relates to their environment and health. A change in health and environment can change how a person perceives his or her role. Furthermore, an individual's response to change can be influenced by internal (attitude, knowledge, cultural beliefs) and external factors (social support, socio-economic status) (Meleis, 2010). Within this study, some individuals spoke about their frustration of 'waiting for assistance' from care staff to attend to personal needs and the importance of maintaining their own independence and 'identity'. They expressed annoyance and resentment that staff were preventing them from doing the things they wanted to do or were taking their independence away by doing things for them that they were able to manage themselves. Such staff behaviour was construed as restrictive and limiting autonomy. These experiences are also echoed in the findings of Paddock et al. (2019), who suggested that institutional restrictions, standardised routines and strict risk management policies can threaten individuals' independence and autonomy. It has been recognised that when independence is removed from a person's life, an individual can feel defeated, depressed or begin to doubt their own ability to care for themselves (Wiersma and Dupuis, 2010; Custers et al., 2012). Moreover, low expectations can lead to reduced capabilities and can be self-fulfilling, causing deterioration in health and cognitive ability (Chin and Quine, 2012; Lee et al., 2013; Zamanzadeh et al., 2016) and in the worst case scenario, the loss of independence can lead to the loss of a will to live: 'I would rather die than live in a care home' (Österlind et al., 2017). For all the individuals involved in this study, the importance of 'wanting' to re-establish links with family and home was identified as an influential factor in moving to a care home. This included the maintaining of relationships with family members and friends as well as the development of new relationships with staff (Saunders and Heliker, 2008; Lee, 2010; Sussman and Dupuis, 2012; Brandburg et al., 2013; Falk et al., 
2013; Ryan and McKenna, 2015). Some individuals who were 'wanting to connect' with other individuals within the home identified difficulty in developing relationships, citing frailty as an inhibiting factor (Lee et al., 2013). In addition, developing interpersonal relationships with staff was perceived both positively, 'they treat you like one of their own', and less favourably, 'they just do what they have to', illustrating less-meaningful relationships (Eika et al., 2014). The significance of relationships is highlighted within the systematic review of Fitzpatrick and Tzouvara (2019). The authors related potential facilitators and inhibitors that corresponded with Meleis's personal and community transition conditions within the theme of interpersonal connections and relationships for older people. These connections centred on co-residents, care facility staff, family and significant others beyond the care facility. Moreover, when considering how relationships can be created and sustained, the Senses framework of Nolan et al. (2006) identifies six senses that are seen as prerequisites for good relationships within the context of care and service delivery, and that essentially good care can only be delivered when the 'senses' are experienced by all the groups involved. The Senses framework recognises the importance of each person in a relationship experiencing a sense of significance and feeling that they matter as a person.

Research has identified that following care home admission, individuals can lose their previous social networks and are unable to create new ones (Zamanzadeh et al., 2016) and are at risk of feeling lonely and isolated (Brownie et al., 2014). Moreover, it is recognised that care staff have an important role to play in encouraging new individuals to develop new relationships (Cooney, 2012; Križaj et al., 2018). Conversely, Eika et al. (2014) stated that staff lacked awareness about the impact of the transition for the older person and their next of kin when moving to a care home. Moreover, staff must be aware of the feelings surrounding the move for both the individual and their families, such as missing loved ones and loneliness (Ellis and Rawson, 2015). Therefore, care home staff and family have the potential to support each individual's identity by maintaining relationships and promoting new social connections. This is in keeping with the guidelines of the National Institute for Health and Care Excellence (2015) which indicate that an individual's care plan should include ordinary activities outside the home to encourage participation in the community, reduce social isolation, and build personal confidence and emotional resilience.

The findings from this study clearly identify that for the majority of individuals the first four- to six-week period following entry to a care home was unsettling, and for some an upsetting experience. This study is significant because the data were collected in the early post-relocation phase and there is limited research that has explored the experiences and perspectives of older people during this crucial time period. Moving home has already been identified as a major life stressor for an older person (Ellis, 2010; Brandburg et al., 2013; Sury et al., 2013; Ryan and McKenna, 2015). Our study has identified that individuals report having experienced a loss of autonomy, independence and identity, making adjustment to life in a care more challenging, with individuals trying to cope with new familiarities and care routine practices with little direction or guidance (Bradshaw et al., 2012; Cooney, 2012; Brandburg et al., 2013; Rieldl et al., 2013; Ericson-Lidman et al., 2014; Križaj et al., 2018). 


\section{Conclusion}

It is very important that individuals who move to a care home are enabled to lead full and purposeful lives, and to realise their ability and potential. Maintaining continuity between the person's past and present role is an important factor in the adaption process. Within this study, care home staff were primarily perceived as providers of health-care delivery only and not as people with whom to develop relationships. It is important that both care home staff and individuals actively seek out opportunities for engagement with the wider community. Care home managers should be willing to look beyond traditional models of support and seek voluntary/community organisations to undertake personalised social care support. 'My Home Life' is an international initiative that aims to promote quality of life and positive change in care homes for older people. Creating a sense of community is at the heart of 'My Home Life', not only between residents, relatives and staff but also between care homes and their local communities through community engagement events and inter-generational activities. It is through connection with family and friends, and by engaging with communities, that wellbeing can be enhanced and feelings of 'Waiting and Wanting' minimised. Key recommendations from this study include the need to raise awareness of the significance of this critical time period and to amend policy and practice accordingly. This could include the development of a bespoke induction programme for each new resident facilitated by a senior member of the care home staff with overall responsibility for working in partnership with individuals and families, in addition to the broader health and social care team. The uniqueness and intrinsic value of individuals should be acknowledged in partnership with the individual and their relatives that includes their values and preferences in terms of physical and psychological safety and promoting independence. The promotion of maximum independence and rehabilitation should be afforded by all care staff taking account of advice and recommendations from relevant health and social care professionals to support a more positive transition for new residents, relatives and care home staff. Therefore, it is imperative that individual and human rights are safeguarded and actively promoted within the context of services provided by the home and an individual should have access to all the information and advice they need to make informed decisions, including advocacy services.

\section{Limitations of study}

It is recognised that 70 per cent of people in care homes have dementia or severe memory problems (Alzheimer's Society, 2019). The exclusion of older people with cognitive impairment may be seen as a limitation of this study. However, as the study was carried out over a 12-month period and relied on participants' ability to recall and reflect on their experiences in an interview situation, it was important to select participants who would ensure that the residents' voice was heard as this is often absent from this type of research.

Acknowledgements. The authors would like to thank all the older people who participated in the study and the care managers and care home managers who assisted with recruitment. 
Author contributions. All authors have agreed on the final version and meet all four International Committee of Medical Journal Editors criteria for authorship: substantial contributions to conception and design, acquisition of data, analysis and interpretation of data, and drafting the article or revising it critically for important intellectual content.

Financial support. This work was supported by a Martha McMenamin Scholarship (MON).

Conflict of interest. The authors declare no potential conflicts of interest with respect to the research, authorship and/or publication of this article.

Ethical standards. Ethical approval for the study was obtained through the Ethics Filter Committee of Ulster University, the Office for Research Ethics Committees Northern Ireland, and the Clinical and Social Care Governance Committee of the Health Care Trust.

\section{References}

Alzheimer's Society (2019) Facts for the Media. London: Alzheimer's Society. Available at https://www. alzheimers.org.uk/about-us/news-and-media/facts-media.

Backhouse T, Kenkmann A, Lane K, Penhale B, Poland F and Killett A (2016) Older care-home residents as collaborators or advisors in research: a systematic review. Age and Ageing 45, 337-345.

Bland M (2005) The challenge of feeling 'at home' in residential aged care in New Zealand. Nursing Praxis in New Zealand 21, 4-12.

Bradshaw S, Playford E and Riazi A (2012) Living well in care homes: a systematic review of qualitative studies. Age and Ageing 41, 429-440.

Brandburg GL (2007) Making transition to nursing home life: a framework to help older adults adapt to the long-term care environment. Journal of Gerontological Nursing 33, 50-56.

Brandburg G, Symes L, Mastel-Smith B, Hersch G and Walsh T (2013) Resident strategies for making a life in a nursing home: a qualitative study. Journal of Advanced Nursing 69, 862-874.

Bridges W (2004) Transitions: Making Sense of Life's Changes. Cambridge, MA: Da Capo Press.

Brownie S, Horstmanshof L and Garbutt R (2014) Factors that impact individuals' transition and psychological adjustment to long-term aged care: a systematic literature review. International Journal of Nursing Studies 51, 1654-1666.

Bull MJ and McShane RE (2008) Seeking what's best during the transition to adult day health services. Qualitative Health Research 18, 597-605.

Chin L and Quine S (2012) Common factors that enhance the quality of life for women living in their own homes or in aged care facilities. Journal of Women and Ageing 24, 269-279.

Clarke L and Bennett E (2013) 'You learn to live with all the things that are wrong with you': gender and the experience of multiple chronic conditions in later life. Ageing \& Society 33, 342-360.

Cooney A (2012) 'Finding home': a grounded theory on how older people 'find home' in long-term care settings. International Journal of Older People Nursing 7, 188-199.

Corbin J and Strauss A (2008) Basics of Qualitative Research, 3rd Edn. Thousand Oaks: CA: Sage.

Custers AF, Westerhof GJ, Kuin Y, Gerritsen DL and Riksen-Walraven JM (2012) Relatedness, autonomy, and competence in the caring relationship: the perspective of nursing home individuals. Journal of Aging Studies 26, 319-326.

Department of Health, Social Services and Public Safety (2006) Safeguarding Vulnerable Adults Regional Policy \& Guidance. Belfast: Department of Health, Social Services and Public Safety.

Eika M, Espnes GA and Hvalvik S (2014) Nursing staff's actions during older residents' transition into long-term care facility in a nursing home in rural Norway. International Journal of Qualitative Studies on Health and Well-being 9, 24105.

Ellis JM (2010) Psychological transition into a residential care facility: older people's experiences. Journal of Advanced Nursing 66, 1159-1168.

Ellis JM and Rawson H (2015) Nurses' and personal care assistants' role in improving the relocation of older people into nursing homes. Journal of Clinical Nursing 24, 2005-2013.

Ericson-Lidman E, Larsson LL and Norberg A (2014) Caring for people with dementia disease (DD) and working in a private not-for-profit residential care facility for people with DD. Scandinavian Journal of Caring Sciences 28, 337-346. 
Falk H, Wijk H, Persson L and Falk K (2013) A sense of home in residential care. Scandinavian Journal of Caring Sciences 27, 999-1009.

Fitzpatrick JM and Tzouvara V (2019) Facilitators and inhibitors of transition for older people who have relocated to a long-term care facility: a systematic review. Health and Social Care in the Community 27, e57-e81.

Folstein MF, Folstein SE and Mchugh PR (1975) Mini-mental state. A practical method for grading cognitive state of patients for the clinician. Journal of Psychiatry Res 12, 189-198.

Fraher A and Coffey A (2011) Older people's experiences of relocation to long-term care. Nursing Older People 23, 23-27.

Grant J, Brutscher PB, Kirk S, Butler L and Wooding S (2009) Capturing Research Impacts: A Review of International Practice. Cambridge: RAND Europe.

Heliker D and Scholler-Jaquish A (2006) Transition of new residents: basing practice on residents' perspective. Journal of Gerontological Nursing 32, 34-42.

Holtslander LF and Duggleby WD (2009) The hope experience of older bereaved women who cared for a spouse with terminal cancer. Qualitative Health Research 19, 388-400.

Hutchinson S, Hersch G, Davidson HA, Chu AYM and Mastel-Smith B (2011) Voices of elders: culture and person factors of residents admitted to long-term care facilities. Journal of Transcultural Nursing 22, 397-404.

International Council of Nurses (2006) Code of Ethics for Nurses. Available at http://www.icn.ch/abouticn/code-of-ethics-for-nurses/.

Iwasiw C, Goldenberg D, Macmaster E, McCutcheon S and Bol N (1996) Residents' perspectives of their first 2 weeks in a long-term care facility. Journal of Clinical Nursing 5, 381-388.

Johnson R and Bibbo J (2014) Relocation decisions and constructing the meaning of home: a phenomenological study of the transition into a nursing home. Journal of Aging Studies 30, 56-63.

Johnson R, Popejoy L and Radina M (2010) Older adult's participation in nursing home placement decisions. Clinical Nursing Research 19, 358-375.

Keister KJ (2006) Predictors of self-assessed health, anxiety, and depressive symptoms in nursing home residents at week 1 post relocation. Journal of Aging and Health 18, 722-742.

Komatsu M, Hamahata A and Magilvy JK (2007) Coping with the changes in living environment faced by older persons who relocate to a health-care facility in Japan. Japan Journal of Nursing Science 4, $27-38$.

Križaj T, Warren A and Slade A (2018) 'Holding on to what I do': experiences of older Slovenians moving into a care home. The Gerontologist 58, 512-520.

Lee DTF (1999) Transition to residential care: experiences of elderly Chinese people in Hong Kong. Journal of Advanced Nursing 30, 1118-1126.

Lee DTF (2001) Perceptions of Hong Kong Chinese elders on adjustment to residential care. Journal of Interprofessional Care 15, 235-244.

Lee DTF (2010) Predictors of adjustment to nursing home life of elderly residents: a cross-sectional survey. International Journal of Nursing Studies 47, 957-964.

Lee DTF, Woo J and Mackenzie A (2002) A review of older people's experiences with residential care placement. Journal of Advanced Nursing 37, 19-27.

Lee V, Simpson J and Froggart K (2013) A narrative exploration of older people's transitions into residential care. Aging and Mental Health 17, 48-56.

Lincoln Y and Guba E (1985) Naturalistic Inquiry. Newbury Park, CA: Sage.

Lindley $\mathbf{S}$ and Wallace $\mathbf{J}$ (2015) Placing in age: transitioning to a new home in later life. ACM Transactions on Computer-Human Interaction 22, 20.

Maz J (2013) Employing grounded theory approach: core characteristics. British Journal of Cardiac Nursing 8, 453-458.

Meleis AI (2010) Transitions Theory - Middle Range and Situation Specific Theories in Nursing Research and Practice. New York, NY: Springer.

Minhat HS, Rahmah MA and Khadijah S (2013) Continuity theory of ageing and leisure participation among elderly attending selected health clinics in Selangor. International Medical Journal Malaysia 12, 51-58. 
Moore KD and Ryan AA (2017) The Lived Experiences of Nursing Home Residents in the Context of the Nursing Home as Their 'Home'. A Grounded Theory Study (Main Report). Ulster University and Nursing Homes Ireland. lster University.

Morse JM (2009) Exploring transitions. Qualitative Health Research 19, 431.

Morse JM, Stern PN, Corbin J, Bowers B, Charmaz K and Clarke AE (2009) Developing Grounded Theory: The Second Generation. Walnut Creek, CA: Left Coast Press.

Munhall PL (2012) Nursing Research. A Qualitative Perspective, 5th Edn. edn, Sudbury, MA: Jones \& Bartlett Learning, C2012.

National Institute for Health and Care Excellence (2015) Transition Between Inpatient Hospital Settings and Community or Care Home Settings for Adults with Social Care Needs (NG27). Available at https:// www.nice.org.uk/guidance/ng27/chapter/Recommendations\#discharge-from-hospital.

Nolan MR, Hanson E, Magnusson L and Anderson B (2003) Gauging quality in constructivist research: the Aldre Vast Sjuharadmodel revisited. Quality in Ageing 4, 22-27.

Nolan M, Brown J, Davies S, Nolan J and Keady J (2006) The SENSES Framework: Improving Care for Older People Through a Relationship-centred Approach. Sheffield, UK: University of Sheffield.

O'Neill M, Ryan A, Tracey A and Laird EA (2020) 'You're at their mercy': older peoples' experiences of moving from home to a care home: a grounded theory study. International Journal of Older People Nursing 15, e12305.

Österlind J, Ternestedt BM, Hansebo G and Hellström I (2017) Feeling lonely in an unfamiliar place: older people's experiences of life close to death in nursing home. International Journal of Older People Nursing 12, e12129.

Paddock K, Brown Wilson C, Walshe CE and Todd C (2019) Care home life and identity: a qualitative case study. The Gerontologist 59, 655-664.

Porter EJ and Ganong L (2005) Older widows' speculations and expectancies concerning professional home-care providers. Nursing Ethics 12, 507-521.

QSR International (2018) NVivo Qualitative Data Analysis, Version 12. Melbourne: QSR International.

Regulation and Quality Improvement Authority (2020) Guidance for the public clicks into the definition of a nursing and residential home. Available at https://www.rqia.org.uk/guidance/guidance-for-the-public/frequently-asked-questions-for-public/.

Riedl M, Mantovan F and Them C (2013) Being a nursing home resident: a challenge to one's identity. Nursing Research and Practice 2013, 932381.

Ryan A and McKenna H (2015) 'It's the little things that count'. Families' experience of roles, relationships and quality of care in nursing homes. International Journal of Older People Nursing 10, 38-47.

Saunders JC and Heliker D (2008) Lessons learned from 5 women as they transition into assisted living. Geriatric Nursing 29, 369-375.

Strauss A and Corbin J (1990) Basics of Qualitative Research. Thousand Oaks, CA: Sage.

Strauss A and Corbin J (1998) Basics of Qualitative Research: Techniques and Procedures for Developing Grounded Theory, 2nd Edn. Thousand Oaks, CA: Sage.

Sullivan GJ and Williams C (2017) Older adult transitions into long-term care. Journal of Gerontological Care 43, 41-49.

Sullivan L and Willis DG (2018) Towards changing the long-term care (LTC) paradigm: explicating the concept of thriving in older adults living in LTC. Issues in Mental Health Nursing 39, 388-397.

Sury L, Burns K and Brodaty $\mathbf{H}$ (2013) Moving in: adjustment of people living with dementia going into a nursing home and their families. International Psychogeriatrics 25, 867-876.

Sussman T and Dupuis S (2012) Supporting a relative's move into long-term care: starting point shapes family members' experiences. Canadian Journal on Aging 31, 395-410.

Sussman T and Dupuis S (2014) Supporting individuals moving into long-term care: multiple layers shape individuals' experiences. Journal of Gerontological Social Work 57, 438-459.

Tanner D (2010) Managing the Ageing Experience: Learning from Older People. Bristol, UK: Policy Press.

Tsai HH and Tsai YF (2008) A temporary home to nurture health: lived experiences of older nursing home residents in Taiwan. Journal of Clinical Nursing 17, 1915-1922.

Walker E and McNamara B (2013) Relocating to retirement living: an occupational perspective on successful transitions. Australian Occupational Therapy Journal 60, 445-453. 
Walker CA, Curry LC and Hogstel MO (2007) Relocation stress syndrome in older adults transitioning from home to a long-term care facility: myth or reality? Journal of Psychosocial Nursing and Mental Health Services 45, 38-45.

Wiersma E and Dupuis SL (2010) Becoming institutional bodies: socialization into a long-term care home. Journal of Aging Studies 24, 278-291.

Wilson SA (1997) The transition to nursing home life: a comparison of planned and unplanned admissions. Journal of Advanced Nursing 26, 864-871.

Wilson CB and Clissett $\mathbf{P}$ (2011) Involving older people in research: practical considerations when using the authenticity criteria in constructivist inquiry. Journal of Advanced Nursing 67, 677-686.

Zamanzadeh V, Rahmani A, Pakpour V, Chenoweth LL and Mohammadi E (2016) Psychosocial changes following transition to an aged care home: qualitative findings from Iran. International Journal of Older People Nursing 12, e12130.

Cite this article: O'Neill M, Ryan A, Tracey A, Laird L (2022). 'Waiting and Wanting': older peoples' initial experiences of adapting to life in a care home: a grounded theory study. Ageing \& Society 42, 351-375. https://doi.org/10.1017/S0144686X20000872 